\title{
Decentralization and Role of School Development Committees (SDC) In the Public Schools in Sri Lanka: Case Study in the Colombo District
}

\author{
CHANDANA KASTURI ARACHCHI \\ Dept. of Social Science Education, Faculty of Education, \\ University of Colombo, Colombo 03, Sri Lanka \\ chaou05@yahoo.com /chacmb@gmail.com
}

\begin{abstract}
This paper discusses the nature of the implementation of School Development Committees $(S D C)$ in the government school sector in Sri Lanka. The Programme of School Improvement (PSI) is being implemented in Sri Lanka since 2006. According to the PSI regulations and guidance, schools are anticipated to form School Development Committees (SDC) to make school decisions. Main research question in this study is: "how is the SDC implementation in the Colombo district government schools?" The nature of this study is qualitative inquiry, and multiple case study approach was used to inquire this research problem. Five schools were selected purposively, and five principals, five deputy principals, fifteen teachers and fifteen parents were comprised in the sample. Document survey, questionnaire and semi structured interviews were used to gather information in this study. Data was analyzed using thematic analysis technique. Since the PSI implementation, the decision making process has been significantly changed. It seems that, most schools do not implement authentic democratic and participatory decision making style and participatory management approaches in school management. Most of the principals still perform the key role in decision making in the schools. Principal's responsibility and accountability has been improved since hel she has to execute new roles in school management. Lack of resources, negative attitudes and lack of awareness of the stakeholders are the key barriers to perform role of the SDC. Therefore, it is imperative to organize PSI awareness programmes since the stakeholders do not have better understanding on PSI or SBM. In addition, it is necessary to establish an administrative body to supervise PSI implemented schools, and to guide SDC members.
\end{abstract}

Key Words: School Development Committee, Principal Role, Participatory Decision Making, Programme of School Improvement, School Based Management 


\section{Background of the Study}

This study investigated the role of School Development Committee (SDC) in the schools where the programme of school improvement (PSI) is being implemented in the Colombo district, Sri Lanka. In particular, it was explored the impact of the PSI, introduced by the Ministry of Education in 2006, for decision making in the schools. School Based Management (SBM) system in the government schools in Sri Lanka was started to implement as the Programme of School Improvement (PSI) since 2006. Before to the PSI implementation most of the decisions related to schools activities were made by the Principals of the government schools. Although government schools had School Management Committees (SMC), most of the members of the committees did not get themselves involved in the decision-making process. They did not concern of their responsibility in making important decisions related to the school activities (Perera, 1998; Fernando, 1986).Therefore, it was encountered many issues related to management and criticism against school management (Perera \& Palihkkara, 1997). As a solution, the Ministry of Education in Sri Lanka (MOESL) implemented the Programme of school Improvement (PSI) in the government schools in Sri Lanka (Ministry of Education, 2005; "National Education Commission Report," 2003).

In order to increase effectiveness of the PSI system, School Development Committee (SDC) and School Management Team (SMT) were introduce as main decision making boards in the schools. The SDC members are responsible for preparing school policy, setting out mission, objectives, strategies, and making all key decisions. Stakeholders are supposed to be involved in preparing school development plans, annual plans and project plans. The Ministry of Education expected many things in implementing the PSI. One of them is develop and maintain a very close relationship with the different community members by the school. The Ministry of Education has provided guidance and instructions to the schools to implement PSI in their schools. Formulation of SDC is a very important aspect of the PSI. Principal of the school is the Chairperson of the SDC, and one of the deputy principals of the relevant school, teachers, old pupils, parents, and one education officer from the Zonal education office represent the SDC. The School Management Team (SMT) takes necessary actions to implement the decisions, which are made by the SDC. The composition of the SMT is determined by the SDC and the Chairperson of the SMT is the principal of the relevant school. (Ministry of Education, 2005, 2008). Occasionally, members of the SMT assist the 
SDC to make decisions when necessary. Accordingly, the decision making process was changed in the government schools following to the implementation of the programme of school improvement. Consequently, other necessary changes have been also materialized and the role of the school managers' was changed accordingly. The principal and the other members of the school community are supposed to be adapted to the PSI changes and to the new environment in the school.

Participatory decision making, community participation for school activities, school autonomy and school based staff development programmes are key elements of the PSI system in Sri Lanka. The PSI management system is different than the earlier management system that practiced by the government schools in Sri Lanka. Therefore, it is vital for studying about the implementation of the programme of school improvement in the schools. Researchers have carried out many studies on SBM in other countries. Although there is a small number of survey research carried out on PSI in Sri Lanka, but there is no satisfactory number of qualitative research studies undertaken on the implementation of the PSI in the schools. And especially lack of qualitative and in-depth studies have been carried out in relation to the PSI in Sri Lankan schools. Therefore, the findings of this research may be very useful for the decision makers in the PSI schools and the policy makers in education sector in Sri Lanka.

Decentralization is one of the key elements of the SBM, and most countries implementing SBM include decentralized decision-making as a part of the process (Osorio, Fashih, Patrinos, \& Santibanez, 2009). Decentralization of decision making power and responsibility to the school level is expected by the Ministry of Education in Sri Lanka through implementing the Programme of School Improvement (PSI). In the Sri Lankan context, PSI involves the delegation of power, authority, and responsibility to the school level by higher education authority (Ministry of Education, 2008).

Leithwood and Menzies (1998) identified four models of school based management as:

(1) Administrative control model - the principal, as representative of the education administration, is dominant;

(2) Professional control model - the teaching staff receives the authority;

(3) Community control model - a local group or the parents, through a board, are in charge; 
(4) Balanced control model - the parents and the professionals (teachers and principal) share authority equally.

Some of the above characteristics are reflected in the PSI programme in Sri Lanka. However, the Ministry of Education expects to implement balance controlled model of SBM in Sri Lanka. However, according to the anecdotal evidences, schools in Sri Lanka are still implementing PSI as professional control model. Therefore, school leaders must be empowered to shift from professional control model to balance control model. Balance control model emphasizes community participation in management from outside and inside school rather equally.

School Based Management (SBM) has become the most famous element of public school management in most countries around the world (Osorio, Patrinos, \& Fasih, 2009). SBM is being increasingly advocated as a shortcut to more efficient management and quality improvement in education. Especially in developing countries, concerns remain about the possible detrimental impact of SBM on school quality; equity among different schools in the same system; the motivation of and relationships between principals and teachers; and financial as well as administrative transparency (Botha, 2012; Gamage, 2009; Mokoena, 2012; Patrinos, 2009). International experience of SBM can be used for improvement of the effectiveness of the PSI system in Sri Lanka.

The number of articles converse merits and demerits of SBM. Some authors argue that SBM is the panacea for quality improvement, while others argue that its introduction has led to deterioration in quality, especially in the marginalized schools. However, the merits and demerits of SBM are decided on the strategies used by the education authorities of varies countries for the implementation of this policy in their school system. Lugaz and De Grauwe (2005) argue that the lack of transparency, especially in the use of funds at school level by the principal and the school board as a challenge for smooth functioning of SBM in many countries. Recently completed research by the International Institute for Educational Planning (IIEP) on school functioning in the context of decentralization in West Africa shows that parents and teachers have no proper knowledge or control over the use of the fees which they pay for their children's schooling (Lugaz and De Grauwe, 2005). According to the anecdotal evidences decision makers in the Sri Lankan schools also face many challenges in implementing the PSI policy. However, problems and challenges are naturally emerged when implementing any new policy in any field. It is also common to the Sri Lankan context as 
well. Relevant international research findings also useful to understand the real global experience of SBM, and the research findings of local researches are helpful to find solutions for the problems that faced by school leaders in implementing the PSI in Sri Lanka. Therefore, the researchers in the field of education in Sri Lanka have a huge responsibility on that.

The study location of this research is Colombo district school in Sri Lanka. In this study, it was investigated the role of the SDC in the PSI implemented schools in Sri Lanka. In addition, in this study it was examined stakeholders' perceptions regarding the SDC operation in the schools. In particular, identified and evaluated the constraints and challenges which are related to the role of SDC in the PSI implemented schools. This study is very much useful because, since 2006, the decision making power and the authority has been transferred to the school level through the PSI programme (Ministry of Education, 2008). So far, no adequate research has been undertaken to investigate the role of SDC in the PSI implemented schools. Especially, researchers have not paid their attention to explore perspectives and experiences of staff and stakeholders in the schools in this regard. The findings in this study may be useful for getting a better understanding of the implementation of SDC in the PSI schools in Sri Lanka. Moreover, the findings in this study may also be useful for future policy decisions on the PSI in Sri Lanka.

\section{Statement of the Research Topic/ Problem}

This study focused on the functions of SDC in the schools where the School Based Management (SBM) programme is being implemented in Sri Lanka. The Sri Lankan version of SBM was introduced as a pilot project in 2006 which titled as the "Programme of School Improvement" (PSI). At present, PSI is being implemented in the government schools in Sri Lanka. Accordingly, most of those schools have been implementing the programme of school improvement for more than six years, and SDC can be identified as most important decision making body in the PSI implemented schools. In addition, this study explored the experiences of the SDC members: including principals, deputy principals, teachers and parents on the role of SDC in the PSI implemented schools. Respondents have much experience on SDC operation since they have been representing the SDC for many years.

Many countries have been implementing School Based Management (SBM) in their school system for more than three decades. Researchers have done many studies on the SBM, and 
therefore, it has a number of definitions, which reflect how different countries apply it. There are, however, common characteristics. According to Banicky (2000), several terms commonly used to describe this localized governance model include "Decentralization, Restructuring, Site-Based Management, Participatory Decision-Making, Shared Decision Making, and School-Based Decision Making” (p. 3). De Grauwe (2005) suggested that SBM basically means "the transfer of decision-making power on management issues to the school level" (p. 1). Further Caldwell (2005) described the SBM as "systematic and consistent decentralization to the school level of authority and responsibility to make decisions on significant matters related to school operations within a centrally determined framework of goals, policies, curriculum, standards and accountabilities" (p. 3). It seems that SBM is a systematic decentralization of authority, decision making power to the school level to make their decisions as their own. It is included delegation of power, authority and responsibility to the local schools by the central education authority. In addition, the SBM schools are given autonomy to make their decisions in democratic and participatory manner at school level. Hence, it is expected to amplify much community participation in school decisions and increases the perform of various school activities. The PSI encourages stakeholders of school for participation in school management, and in particular for school planning and decision making process.

For the purpose of this study, SBM was identified as a decentralization process of decision making power and responsibility which make opportunity to empower the school community members. Decentralization is one of the key elements of SBM and most countries implementing SBM that include decentralized decision-making as a part of the process (Osorio, Fashih, Patrinos, \& Santibanez, 2009). Decentralization of decision making power and responsibility at the school level is expected by the Ministry of Education in Sri Lanka through the Programme of School Improvement (PSI). In the Sri Lankan context, PSI involves the delegation of power, authority, and responsibility at the school level by the education authority and seeks accountability for school decisions making process (Ministry of Education, 2008). Through decentralization, the schools having more autonomy for making their own decisions. Furthermore, Ministry of Education expects more community participation in school decisions.

Raihani (2007), Briggs \& Wohlstetter (2003) and Cheng (1993) identify some common characteristics of SBM implementing school, such as a shared mission, school based staff 
development activities, participation of the principal, teachers, and parents in decision making, shared school leadership among administrators and teachers, participatory and democratic decision-making in the school, and power distributing throughout the school. These are new to the PSI schools in Sri Lanka as they had not practiced participatory decision making earlier. Some of these characteristics are reflected in the Sri Lankan PSI programmes. Examples are: participation of the principal, deputy principal and representatives of teachers, past pupils and parents in school decision making, delegation of decision-making power among school staff. The PSI in Sri Lanka is expected to increase transparency about school activities for the public. In the PSI system, relatively there are opportunities for more stakeholders to be involved in school decisions rather than the former school management system. Therefore, the decisions are more open to the public (Ministry of Education, 2008). Many public schools in Sri Lanka have been implementing the PSI system for more than six years. However, anecdotal evidences indicated that many schools in Sri Lanka do not implement the Sri Lankan version of SBM, the Programme of School Improvement in proper manner. In addition they are facing many difficulties in implementing the PSI in their schools. Especially, in decision making, many schools face many different challenges such as: finding out suitable members for the SDCs, selecting people for the SDC, contribution made by the members of SDC, awareness of SDC members on the PSI, management and leadership skills of the SDC members, and rules and regulation obstructs for proper implementation of the PSI. In addition, generally most of the members of the SDC face challenges in findings avenues for participating in school management. Some schools do not welcome ideas of outside community members. Anecdotally, it seems that the managers and leaders of the government schools face many challenges in implementing the PSI in their schools. Therefore, formal research findings and proper evidences needs to understand real situation in the implementation of the PSI. Consequently, school development committee has to play a vital role in implementing the PSI in schools. Therefore, carrying out of this study is very helpful to get a better understanding of the implementation of the PSI and the role of the SDC in schools. In order to that, this study aimed to explore the experiences of the SDC members on the implementation of the PSI in their schools. As objectives of this study, it was aimed to; identify the nature, functions, formulation and practicing of school development committee in the schools where the Programme of School Improvement (PSI) is being implemented, examine the perception of the community members in the process of implementing the SDC and decision making at the government schools in Sri Lanka, examine 
the nature of the participation of community members for the decision making process in the PSI implemented schools, and identify challenges faced by the members of SDC in implementing the Programme of School Improvement in Sri Lanka.

\section{Methodology}

\section{Statement of the Research Problem and Objectives of the Study}

In this study, it was investigated the role of the SDC in the schools where the programme of school improvement is being implemented in the Colombo district, Sri Lanka. The main research question and the objectives of this research are as follows;

\section{Main Research Question}

How is the SDC being functioned in the PSI implemented schools in the Colombo district?

\section{Objectives of the Study}

1. Identify the formulation and implementation of SDCs in the PSI implemented schools.

2. Study the nature of participation of the community members in the SDC decision making process in the PSI implemented schools.

3. Identify constraints and challenges that are related to SDC operation in the PSI implemented schools.

\section{Introduction of the Methodology}

This section discusses the methodology which was used to examine the role of the SDC at the schools located in the Colombo district in Sri Lanka. In order to examine the role activities of SDCs in the PSI implemented schools, this research followed qualitative inquiry. With special reference to the Colombo district, $1 \mathrm{AB}$ schools were selected, and the researcher used a case study approach for the survey. Several data collection methods were employed in this study such as: document analysis, questionnaires and personal interviews. Data were analyzed using qualitative and descriptive analytical methods.

\section{Research Paradigm}

There are number of research paradigms commonly used in educational research. Bassey (1999) defines a paradigm as "A network of coherent ideas about the nature of the world and the function of researchers which, adhered to by a group of researchers, conditions and the 
patterns of their thinking and underpins their research actions" (Bassey, 1999 in Morrison, 2007, p. 19). According to Filstead (1979) paradigm can be identified as a set of interrelated assumptions about the social world.

Cohen et al., (2007) stated that the research within the interpretive paradigm is often small scale, reaching social life, non-statistical, subjective, personal involvement of the researcher, interpreting the specific and individual perspective. It can be identified three key types of research paradigms as positivism, interpretive and critical theory (Ponterotto, 2005; W. Willis, Willis, Jost, \& Nilakantha, 2007; Yin, 2009). The interpretive paradigm strives to understand and interpret the human and lived world, socially constructed, reflect understanding and subjective and objective research methods are acceptable (Ponterotto, 2005; Walsham, 2006; J. W. Willis, Willis, Jost, \& Nilakanta, 2007), and interpretive emphasize the goal of understanding the lived experiences of those live it day to day (Ponterotto, 2005). While positivist researchers use experimental design and interpretive researchers mostly use qualitative techniques, like case study method to study the particular research problem.

Since this study expected to understand the role of the SDCs in the PSI schools, interpretive paradigm was good fit as it was aimed to study each school as an individual case and gathered information from stakeholders of schools including principals, deputy principals, teachers and parents in order to explore their experiences of the SDC on the implementation in the $1 \mathrm{AB}$ schools in Sri Lanka. In particular, this study explored the experiences of stakeholders regarding implementation of SDCs in their schools. Therefore, interpretive paradigm was appropriate in this study since this study explored the lived experiences of stakeholders of the PSI schools, and on the other hand, the nature of this study was a small scale, reached social life, and there was a personal involvement of the researcher.

\section{Qualitative Research}

Qualitative research uses a variety of interpretive research methodologies that seek to investigate the quality of relationships and experiences (Wallen \& Fraenkel, 2001). In general, qualitative research focuses on the inner experience of people, as they interact with others. "A primary purpose of qualitative research is to describe and clarify experience as it is lived and constituted in awareness. Human experience is a difficult area to study. It is multilayered and complex, it is ongoing flow" (Polkinghorne, 2005, p. 138). Therefore, the 
qualitative research approach was selected since it was most appropriate in this study, because this research intended to explore live experiences and perceptions of stakeholders of the PSI schools on SDC role in their schools. Especially, since this research expected to uncover the personal experiences of the stakeholders regarding SDC activities and decision making, qualitative research approach was most suitable approach to gather information from participants in this study.

\section{Case Study}

The case study research approach has been used by qualitative and interpretive researchers, for a long time in disciplines (Burns, 2000) since it has a number of advantages. This approach can be used to investigate actual contemporary life settings and life cycles of people, and it allows researchers to retain the holistic and meaningful characteristics of real life events of people (Yin, 2009) While some scholars highlight the advantages of the case study approach, many scholars and authors provide definitions. For example, Mutch (2005) defines case study as: "a study that focuses on a bounded object, usually a person, group, setting, or concept". Alternatively, Simons (2009) provides a definition for case study as "an in-depth exploration from multiple perspectives of the complexity and uniqueness of a particular project, policy, institution, programme or system in a real life context" (Simons, 2009 in Hesse-Biber \& Leavy, 2011). Since this study planned to explore deeply the experience and perspectives of stakeholders in selected schools in Sri Lanka about the SDC role in the PSI implemented schools, it seems that the Simons' definition highlights very significant features that are relevant to this study.

This study investigated the nature and the patterns of SDC role in the PSI implemented schools; SDC implementation was different from school to school in Sri Lanka. In addition, appointing of SDC members for the School Development Committees (SDC), delegation of power, authority, and responsibility was not similar in each school. Therefore, decision making environments, experiences and perspectives of the participants on SDC role in the PSI schools were different. The information collected was very significant in understanding of the actual situation of affairs in relation to the SDC role in the PSI schools in Sri Lanka. The information provided by different participants was helpful to get a better understanding of the actual situation in the SDC role in the PSI schools in Sri Lanka. Therefore, case study approach was well fitted in this study. 


\section{Data Collection and Analysis}

Questionnaires, document surveys and interviews were employed to gather information in this study. Questionnaires and interviews were the main data collection techniques employed to gather information from the principals, deputy principals, teaching staff and parents of the governing boards of schools. As this study planned to gather in depth information from the participants, and this was a qualitative case study research, those instruments were more appropriate to collect data to study the research problem.

\section{Interviewing}

Qualitative researchers use various types of methods for data collection: "observation (participant and non-participant), interviewing, and document analysis" (Ary, Jacobs, \& Razavieh, 2002, p. 430). The interview appears to be the most popular data collection instrument in qualitative research. Interviews allow the researcher to gather direct information from the participants, and the researcher has an opportunity to get more clarifications about the information provided by them. Therefore, it seems that interview is more appropriate method of accessing people's insights, sense, and definitions of situations and constructions of reality. It is also one of the most significant ways that we have of understanding others (Punch, 2009). Various types of interviews are used in qualitative research. These are: semi structured, informal, and retrospective (Wallen \& Fraenkel, 2001). Interpretive researchers believed and tend to prefer semi structured and so called open or unstructured interview (Willis, Jost, \& Nilakanta, 2007). As this study, intended to explore the experiences of the staff and the stakeholders on the SDC role in the PSI schools, interviewing seemed as a suitable method of data collection, because it was seeking particular experiences and perspectives of the stakeholders of schools regarding study phenomenon. Semi structured Interview allows researchers to gather accurate information directly from the participants. In the time of interviewing it has more opportunities to get more clarification in relation to the participants' ideas, opinions, information etc. As this study employed semi structured interviews, then participants had opportunities to present their information freely.

\section{Documentation}

According to Hodder (2000, p. 704) documents are important in qualitative research because "access can be easy and low cost, ... the information provided may differ from and may not available in spoken form, and ... texts endure and thus give historical insight". Atkinson and 
Coffey (2004, p. 59) state that "documentary materials should be regarded as data in their own right. In this case study research, public documents was one of the data sources used. Documents were important because in the nature of the PSI has more paper work, and documents provided the formal frameworks of the PSI. The documents in this research were minutes of the SDC meetings, minutes of the SMT meetings, school plans, policy statements and its related documents, and PSI guidelines etc.

\section{Questionnaire}

In order to gather rich data, a questionnaire survey was used in this study. An advantage of the questionnaire is that: it was used to gather data in a relatively short period of time. Questionnaire is an effective tool to gather straightforward and factual information from participants (Anderson, 1998). The data gathered from questionnaire was used to triangulate data in this study. Therefore, the data gathered from questionnaire was useful to get better understanding of the role of the SDC in the PSI implemented schools. Two kinds of participants involved in the questionnaire survey; teachers and parents. Researcher personally administered the questionnaire, and collected those from the participants, and therefore the response rate was more satisfactory.

\section{Participants}

This study gathered information from principals, deputy principals, teaching staff and parents on the governing boards, who have experiences of the SDC role in the PSI implemented schools in the Colombo district in Sri Lanka. Participants in this study were selected using a purposive sampling method. Best \& Kahn (2006) suggest, purposive sampling permits the researcher to choose the participants who provide the richest information. Sample was comprised the principals from five selected schools, five deputy principals, fifteen teachers and fifteen parents from $1 \mathrm{AB}$ schools in the Colombo district. All to gather 8 participants from each school were represented in this study. Accordingly, total number of 40 participants was participated in this research. 
Table 1: Sample of the study

\begin{tabular}{|l|l|}
\hline Participants & No \\
\hline Principals & 5 \\
\hline Deputy Principals & 5 \\
\hline Teachers & 15 \\
\hline Parents & 15 \\
\hline Total & 40 \\
\hline
\end{tabular}

The principals, deputy principals, teachers and parents in school governing boards had a role in implementing the PSI system in schools in Sri Lanka since 2006. They had valuable experiences as they have been implementing the PSI system in their local schools for more than six years.

\section{Data Analysis}

McMillan and Schumacher (2010) suggest that "qualitative researchers analyze and make meaning from the data, starting with specific data and ending with categories and patterns" (p. 367). Thematic analysis is a qualitative data analyzing strategy that starts in the data, and pursues identifiable themes and patterns (Aronson, 1994). Themes were emerged within the transcribed interview data, questionnaire data and documents data. Those themes were organized, described and interpreted (Braun \& Clarke, 2006; Radnor, 2002). Hitchcock and Hughes (1995) suggest going over transcriptions of interview data, questionnaire data and documents data many times, and eventually meaningful categories will be emerged and then group the data to a few key ideas.

In summary, the participants in this study, principals, deputy principals, teachers and parents of the PSI implemented schools presented their experiences as their real life stories, and those stories were the research data in this study. Thematic analysis is one of the most common approaches of qualitative data analysis (Bryman, 2001; Mutch, 2005), and it was the most appropriate method for analyzing qualitative data, and as this study also had qualitative data in the interview transcriptions, questionnaires and documents. In the process of analyzing the data from the interview transcriptions, questionnaires and documents, it was identified 
themes, then coded and identified patterns in order to find out the similarities between the cases in this study.

\section{Results and Discussion}

\section{Formulation and Implementation of SDC}

Almost all the schools (90\%) have formed SDCs in their schools. For the purpose of formulation of SDCs in the schools, necessary guidance and instructions have been provided by the higher authority through circulars. Therefore, each school should form a SDC according to the guide lines provided by the higher authority (Ministry of Education, 2008). However, it seems that there is no similar mechanism for formulating SDC among all those schools.

Selection mechanism of SDC members is not democratic in most of the schools (more than $60 \%$ ), and principals influence for selecting members for SDC, and SDC members of most schools have been selected by the principal. Some schools (less than $40 \%$ ) have followed instructions given by the higher authority for formulation of SDCs. Consequently, those schools demonstrate democratic decision making culture through SDCs. But, number of those schools is few.

The PSI provides opportunities for community members to be involved in decision-making in the school. Selecting members for the School Development Committees is a very important element in the PSI implementation. According to the information provided by the members of the SDCs, it is understood that the selection mechanism of SDC members is not much democratic. Majority of the teachers and parents (more than 60\%) argues as: "most of the outside members of the SDC are nominated by the principal, and then he asks us to be agreed for his nomination, our duty in the SDC is to approve his agendas". One principal confirms that the above statement as: "principal is the top manager and the chief executive office in the school; helshe is responsible for all the things happened in the school. Therefore the principal must have power to select members for the SDC, and the principal knows very well who should be appointed to the SDC”. It seems that the principals in the PSI schools still have more power in decision making on human resources. It is evident that the participatory management is not being practiced in the majority of PSI implemented schools (more than $60 \%$ ) in this regard. Moreover, one deputy principal said that: "every outside community 
members does not have sufficient knowledge on the concept of the PSI or SBM, and even school management. Therefore we must select knowledgeable members for the SDC, otherwise selection would be ineffective". According to the above statements made by a participant, it is understood that the doors of the schools are still being closed for the outside community since the lack of trust and poor understanding between staff and the outside community members of the school.

Grauwe (2005) states that the pressure by local authorities or communities for a more participatory decision making process has generally been lacking in developing countries. The boards of trustees in New Zealand schools were given wide ranging power and authority, including the employment of staff, negotiation of industrial staff, and the full control of the agreements with the budget (Longe, 1988). Rose (2003) differentiates community participation in schools in Indonesia as ranging from genuine participation to pseudoparticipation. One example, in the beginning of SBM implementation in Alberta, Canada, there were no site councils (Caldwell, 1994), but then in the 1990s site councils were established, and they generally played an advisory role to the principal. In contrast, members of the governing boards of the schools in other countries play a very imperative role, and they have more power in influencing school decisions. Education authorities in Australia face legislation transferring significant powers to the community of SBM schools (De Grauwe 1999).

Deputy Principals and more than sixty percent of teachers of two schools indicated that the participation of outside community members for SDC meetings is very satisfactory in their schools. However, majority of parents and past pupils (more than 70\%), during the interviews, stated that the monthly SDC meeting is seen as a mechanism for informing and consulting with members of the SDCs on school decisions rather than as a mechanism for decision making. However, some schools (less that 40\%) conduct SDC meetings according to the guidance given by the Ministry of Education. SDC members of those schools have good knowledge on the concept of PSI in Sri Lanka. They utilize their knowledge and make effort for implementation of the PSI effectively in their schools.

\section{Community Involvement in the SDC Decision Making Process}

According to the rules, regulations and directions provided by the Central Ministry of Education in Sri Lanka (MOESL), each and every PSI schools are anticipated to establish a 
SDC to make school decisions with the participation of the principal, deputy principals, and representatives of the teachers, parents and past pupils (Ministry of Education, 2005, 2008). The selection process for selecting SDC members must be democratic. However, it seems that selection process is controlled by the principal rather selecting knowledgeable and suitable members for the SDC.

However, the measurement of community involvement in SDCs provides some indicators of low community involvement in decision making and management. The mechanism of selection of members for the SDCs is not transparent, and the community members of the schools lack of knowledge on the selection process in the SDCs. According to the information provided by the majority of parents and teachers of SDCs (more than 60\%), principals of most of the schools influence to select members for the SDCs. Thus, it seems that it is not put into practice a democratic and genuine participatory decision making styles in the PSI schools. Moreover, the SDC meetings is also not been conducted in participatory manner in most of the schools (more than 70\%). One teacher provides proofs for that as: "Community participation in the SDC meetings are only a formality for the purpose of legitimacy. Everything is previously decided by the principal and what is required from the members of the SDC is their agreement and signatures". It is also useful to note that this teacher perceived the role taken by the principal as too dominant in the SDC meetings.

According to the information provided by the majority of respondents excluding the principals (more than 70\%), most of the occasions, only a half or less outside SDC members are invited to attend the monthly SDC meetings, and these are always the same people in each time. It seems that only a limited number of outside SDC members actually attend the SDC meetings. Comments made by the majority of parents $(60 \%)$ during the interviews was that the monthly SDC meeting seen as a mechanism for informing and consulting with members of the SDCs on school decisions rather than as a mechanism for decision making. The principal has previously designed school's plans, and at the meeting level SDC members are asked to approve those plans. It is likely that even though members should be in a position to make amendments, the principal hold more power than they concerning this decision.

Principal as the chairperson of SDC, influences most decisions made by the SDC, and SDC plays a vital role in school management. The SDC makes key decisions regarding school activities. For example, most important financial decisions, decisions in relation to teaching 
and learning process, decision on staff and students matters are made by the SDC. Most decisions on human resource management of the school are taken by the SDC. Especially, decisions for finding resources for school development are also made by the SDC. Therefore, SDC can be considered as the most important decision making body of the government schools in Sri Lanka.

Dimmock (1993) and Caldwell (1994) indicate that the school-based management allows for greater mobilization of resources; Parents and other stakeholders will be more eager to contribute to the funding of their school if they have a voice in the organization and management functions. Through decentralization policy of SBM, a school and its local community is empowered (Daun, 2002). Empowering the school community became more popular in many countries. For example in the United States, Caldwell (1994) writes that in Dade County, Florida, devolving power from state governments to district and then to school levels has been pursued because of the importance given to teacher participation in decision making. In New Zealand, school boards were re-empowered with the structural reform in 1989, when parents were given new responsibilities. This trend towards greater empowerment has also been evident in developing countries in Africa, Asia and Central America (Bray, 2000). It seems that the Sri Lankan model of SBM is rather different than the SBM in most developed countries. Still internal community, staff members control over decision making process in the school. Therefore, outside community members have deficient avenues in involving decision making process in the schools.

\section{Challenges Faced by SDC Committee Members}

Most of the participants explained the challenges faced by them in decision making process in the schools. Majority of principals (more than 60\%) indicate that lack of experience and poor knowledge of the SDC members' on school management as a big challenge. Other SDC members; parents and teachers (more than 70\%) argue about poor leadership qualities of the principals displayed in school management as a huge challenge in decision making. According to majority of principals and teachers (more than 60\%), schools face challenges in finding financial and physical recourses for school development. One of the other major challenges is poor attitudes of the community members towards SDC decisions and school planning. Since most of the community members do not voluntarily provide financial resources, school has to find new ways for finding resources. Some schools (40\%) face challenges in selecting suitable, dedicated, committed and educated community members for 
the SDCs. It seems that the majority of community members have not better awareness on the concept of PSI or SBM. Therefore, they are lack of understanding how to be involved in school decisions in the PSI schools. However, some members of the SDCs have not been empowered for contributing their capacities in utmost level for the school development. School leaders face difficulties since the higher authority of education does not provide proper instructions in time and necessary guidance in relation to the PSI.

Kandasamy and Blaton (2004) indicate that in many developing countries, only a minority of principals are only well- trained professionals. De Grauwe (2005) and Gamage (1993) state that as: increased pressure, especially in terms of time, may render it more difficult for women who also have domestic responsibilities to occupy such posts in SBM schools. Most of the staff members and outside community members cannot spend plenty of time for school activities as they have heavy workload. It seems that members of SDC face many challenges in implementing PSI in their schools. Therefore, it is required a soon intervention of higher education authorities to solve critical problems faced by the schools in implementing the PSI. Challenges are different school to school and province to province, therefore solutions should be matched to the individual school and to the school environment.

\section{Conclusions and Recommendations}

Within the context of education decentralization through the PSI, role of the SDC in school management, particularly access to and control over decision making and challenges faced by the stakeholders was investigated in this study. Overall, the characteristics of community participation in the areas of decision making through SDC, attendance at the meetings related to decision making, and control over financial resources has been changed very slightly as a consequence of the PSI. Moreover, it seems that the schools unwilling to get involved of the external community members may also lead to lack of trust.

It seems that selection process and decision making in the SDC is not much democratic in nature as expected by the PSI planners and higher education authorities. It is evident that participatory management is not being practiced genuinely in most of the PSI schools (more than $60 \%$ ) in decision making process. Most of the decisions made by the principal in the respective school, and/ or he/she directly influence in school decision making. Majority of the members in the SDCs are not inefficiently empowered for participatory decision making in the PSI schools. 
It should be provided several opportunities for the different community members to increase their involvement in setting out school policies, planning and decision-making in the schools. Therefore, appropriate democratic practice should be adopted to establish SDCs, selecting SDC members and conducting SDC meetings. Since the lack of awareness of stakeholders of the schools on the concepts and regulations of the PSI, the SDC and SMT members should be given reasonable opportunity for participation in PSI awareness programmes. Those programmes ought to be organized by the higher education authorities, and in addition, it should be followed by a better monitoring system or governing body to supervise the schools where the PSI is being implemented. Those governing boards have provided necessary inputs for the improvement of this PSI system and would make necessary recommendations and guidance.

\section{Limitations and Further Research Areas}

This study was limited to selected schools where the PSI is being implemented in the Colombo district. It was not study about the other PSI schools in other districts due to limited time, resources and access. This study investigated only about functions of the SDC since the researcher focused to do in depth study that selecting a small sample of school. The sample was limited for SDC members only; thus it was not gathered information from other stakeholders of the schools as this is a case study research. Data collection instruments were also limited to interviews, questionnaire and document survey. So, it was not made effort to gather information through observations due to the time limitation of the researcher. Because of the limitations of this study, there was no opportunity to investigate whole implementation process of the PSI. So, future researchers can study other aspects of the implementation process of the PSI in Sri Lankan schools. For example, financial management in the PSI schools, human resource management in the PSI schools, functions of the school management team in the PSI schools, functions of higher education authority in implementing of the PSI and experiences of the stakeholders of schools on the implementation process of the PSI also research issues to can be investigated by future researchers. 


\section{References}

Aronson, J. (1994). A pragmatic view of thematic analysis. The qualitative report, 2(1), 1-3.

Braun, V., \& Clarke, V. (2006). Using thematic analysis in psychology. Qualitative research in psychology, 3(2), 77-101.

Burns, R. B. (2000). Introduction to research methods. NSW,Australia: Longman.

Carter, B. (2004). How do you analyse qualitative data. Demystifying qualitative research in pregnancy and childbirth, 87-108.

Cheng, Y. C. (1993). The theory and characteristics of school-based management. International Journal of Educational Management, 7(6).

Cranston, N. (2011). School-based management, leaders and leadership: change and challenges for principals. International Studies in Edcuational Administration, 30(1), 2 12.

Goodwin, R. H., Cunningham, M. L., \& Childress, R. (2003). The changing role of the secondary principal. NASSP Bulletin, 87(634), 26-42.

Hesse-Biber, S. N., \& Leavy, P. (2011). The practice of qualitative research (2nd ed.). Los Angeles, USA: Sage Publications, Inc.

Kasturi Arachchi, C. (2011). Educational management (1 ed.). Gothatuwa, Sri Lanka: P\&P Associates.

McMillan, J. H., \& Schumacher, S. (2010). Research in education evidence based inquiry. New York: Pearson.

Ministry of Education. (2005). The programme of school improvement, (2005/24). Ministry of Education, Battaramulla, Sri Lanka.

Ministry of Education. (2008). The programme of school improvement. (2008/35). Ministry of education, Battaramulla, Sri Lanka.

Mutch, C. (2005). Doing educational research: A practitioner's guide to getting started: NZCER Press. 
Osorio, B. F., Fashih, T., Patrinos, H. A., \& Santibanez, L. (2009). Decentralizes decisionmaking in schools, The theory and evidence on School-Based Management Washington,DC.

Polkinghorne, D. E. (2005). Language and meaning: Data collection in qualitative research. Journal of Counseling Psychology, 52(2), 137-145.

Ponterotto, J. G. (2005). Qualitative research in counseling psychology: A primer on research paradigms and philosophy of science. Journal of Counseling Psychology, 52(2), 126136.

Punch, K. F. (2009). Introduction to research methods in education. Los Angeles, USA: Sage.

Radnor, H. (2002). Researching your professional practice. Philadelphia: Open university press, Buckingham.

Sahid, A. (2004). The changing nature of the role of principals in primary and junior secondary schools in South Australia following the introduction of local school management (Partnerships 21). International Education Journal, 4(4), 144-153.

Sergiovanni, T. J. (2001). The principalship: A reflective practice perspective: Allyn \& Bacon/Longman Publishing, a Pearson Education Company, 1760 Gould Street, Needham Heights, MA 02494. Web site: http://www. abacon. com

Walsham, G. (2006). Doing interpretive research. European Journal of Information Systems, 15(3), 320-330.

Wiersma, W., \& Jurs, S. G. (2004). Research methods in education: An introduction: (Sergiovanni).

Wilkinson, D., \& Birmingham, P. (2003). Using research instruments: a guide for researchers: Routledge.

Willis, W., Willis, J. W., Jost, J., \& Nilakantha, R. (2007). Foundations of qualitative research: Interpretive and critical approaches: Sage Publications, Inc.

Yin, R. K. (2009). Case study research: design and methods: Sage Publications, Inc. 
Yu, C. C. Y. (2005). Principal and teacher perceptions of the leadership role of principals in Hong Kong Protestant Christian secondary schools following the change of sovereignty to China. Post Script, 6 (1), 1-22.

\section{Appendices -1}

\section{INTERVIEW PROTOCOL}

\section{How are you involved in the PSI management system?}

\section{Prompts:}

- How did you get started

- How was your training on PSI

- How are you involved in planning of PSI system

- What is your role in implementing PSI in your school

- How are you involved in the decision making in your school

- How easy is PSI system is understand

- What have you done so far

- How did you get prepare to work at the role in PSI

- How is your relationship with other PSI decision makers in the school

- What responsibilities have you in the school in implementing of PSI

- How is your time management in PSI

- What are the other great things about the role of PSI in the school

2. Can you tell me about your experiences of working with PSI in your school?

\section{Prompts:}

- How people involved in the implementation of PSI in your school 
- What help have you been received

- How people helped you to implement PSI in your school

3. Tell me how has your day to day experiences of being at school changed?

4. Can you tell me about challenges you have faced in your role with PSI. Prompts:

- How did you manage in those situations 